\title{
The Fortification System of the Straits. The Evaluations as Decision Support in the Economic Development Strategies of the Metropolitan City
}

\author{
Carmen De Gaetano ${ }^{1, a}$, Tiziana Meduri ${ }^{1, b}$ and Carmela Tramontana ${ }^{1, c}$ \\ ${ }^{1}$ Mediterranea University of Reggio Calabria - PAU - Department of Heritage, Architecture, Urban \\ Planning, Via Salita Melissari - 89124, Reggio di Calabria, Italy \\ acarmen.degatano@unirc.it, btiziana.meduri@unirc.it, 'ccarmen.tramontana@unirc.it
}

Keywords: Conservation Project, Heritage, Partnership, Economic Evaluation, Metropolitan City.

\begin{abstract}
The article discusses the creation of the cultural system of the Strait, is divided into a first part which analyzes the structure of the cultural system, and how important it is for the city of Reggio Calabria, in the second part we analyze the system of fortifications "Umbertine ", where we analyze the system as a resource for the creation of the cultural system and the proposed enhancement and recovery, which are brought to light the criteria used for recovery.
\end{abstract}

\section{Introduction}

The research analyzes the ability of the economic assessment to promote local development. At this stage, we try to shed more light on the importance of this matter, proposing a study on the one hand can highlight the features and the most important aspects of the evaluation and the other is able to demonstrate the operational validity of the latter in promote local development. Local development becomes an important tool for the exploitation of resources of a territory, which takes an active role, offering more and more exploitable resources over time . Finally, it is exposed to the concept of "cultural system" as a model of spatial development can promote the economy of the area and the redevelopment and improvement of the overall livability of a given territory. The culture thus becomes an increasingly important role for territorial marketing in order to improve the quality of life and promote the attractiveness and competitiveness of the territory, in order to activate the factors necessary for its development. The second part is exposed to the project concerning the creation of the cultural system as a process of planning for the future development of the city. A project that involves many actors, especially citizens increasingly seen as behind the choices of a city more efficient. In the context of the current localization economies, in fact, cities are having to compete with each other in pursuit of a development in the long term through investment in the territory and citizens, as an impetus to innovation and research. The three assets to be followed in order to enhance the city will be the ones to make it more welcoming and attractive, with a strong relational identity, sustainable and innovative . Understand, then, as Reggio Calabria to respond to the characteristics of "cultural system" is the goal of this work. Understand what are the reasons that lead a reality, such as that in question, as if to better integrate, to make a place more innovative, both in terms of territorial and cultural, without losing sight of the centrality of the person, respect and protection of human dignity, freedom, and the promotion of interpersonal relationships. The last part of the article focuses on the recovery of the real strong "Umbertini" highlighting the enhancement strategies, highlighting the strong as a resource, highlighting the project and the state of preservation and what are the criteria conservation used.

\section{The system design culture}

Not far away are the days when any attempt to associate the terms "culture" and "economy" when not even irreverent - seemed no doubt risky. Yet the idea that culture can be an engine of growth for the economy of a country is today widely demonstrated and shared by the scientific community. This is a significant mutation of trend that is gradually shifting the meaning of the 
function and use of the cultural property - until recent years reduced to a conceptual category in which the assets were intended as a memory of a cultural identity and therefore a vehicle for education and training - towards a vision that has enriched the profile of a conservative approach much more dynamic and economically productive. If you add to this the picture that is emerging in the era of globalization of markets and which tends, paradoxically, to strengthen the role and significance of territory in its specificity and cultural identity, it is not difficult to imagine how any policy intervention in the sector cultural, if on the one hand can not be separated from the concept of preservation, another must necessarily be open to an interpretation of the territory as a resource, developing planning skills with a strong innovative content. It requires, in this context, the need to "system" and to understand the change as the result of multiple and highly coordinated actions.

If the strategies adopted to date, especially in Italy, have failed to ensure a real and sustainable economic development is compatible because, in reality, have segmented the field and separate the processes of development of cultural heritage from the local context in which they gravitate [1].

The advantage of the cultural consumption of a resource may induce socialized through its reuse by means of enhancement and management is a goal that can be checked with the help of different disciplines.

The enhancement projects are a particular case within the realm of architectural design, but the economic evaluation together with the estimation disciplines continues to be a substantial contribution to the development of design processes. It presupposes, in the case of conservation projects, the presence of value judgments Quantitative alongside qualitative judgments, most often related to the historical interpretation of existing artifacts and building complexes.

The transition from the formal model, which refers to private assets in the current market environment, the model which refers to the Economy substantial public goods with coordinates outside the market, in effect, shifts the focus from consumer use of resources: assets whose value is tied to the exchange and to the prevalence of the logic of the market, but rather resources whose value depends on the use, directly and indirectly from the use and non-use.

The fact that we consider public goods as an economic resource, even if not placed in a context of market rules, raises complex issues, which are not exhausted by simple considerations on the scheme owner of the goods. On the one hand, as I said before, because of the difficulties to attribute a value in the monetary sense, and second, for the different meanings of technical feasibility, economic and financial continue to be a key stage in the planning of interventions on public resources. The territory has always been considered an integral part of our lives, recognized as a place of personal identity, cultural and religious. The desire to tradition, the rediscovery of ancient crafts and the production of typical signs are evident that without a strong local roots there is no significant experience in personal and social life. Among the main human needs is precisely the discovery of the territory, the sense of belonging to someone, even before something. The human being is always looking for a place that satisfies both environmentally and culturally, without which it would live dispersed. Precisely for this reason, in every historical moment has expressed a willingness to change the place where he lived apportandone valid media changes and trying to make it better and appropriate to meet his needs. In an increasingly globalized society, however, many regions are competing with each other and then it is even more difficult to enhance and encourage entrepreneurship in an area, and that is why we need rules and tools, able to promote the product area, also through a communication that is capable of enhancing the development potential and the socio-economic and environmental issues, whilst promoting local entrepreneurship. The territories, in fact, have to fit in the global market, using a fast market and explanatory, communicating the wealth of an area, its entrepreneurial vocations, the location opportunities, business opportunities. These are the tools that support the creation of local businesses and attracting capital from outside the territory, allow you to stimulate economic development.

Through the challenges of globalization has been given a new role in the region, from a competition between economic actors in a competition between local systems. The territory is rediscovered as a complex system, hidden in a highly competitive global dimension : in this step to adopt a strategy of cultural system is critical to the necessity of dealing with homogeneous systems. 
A strategy that is able to exploit the opportunities offered by new communications technologies and extend business opportunities. This work is divided into two parts: the first part will present the concept of cultural and conceptual tools of economic evaluation applied to the product area. In particular, it analyzes the ability of this discipline to promote local development. At this stage, we try to shed more light on the importance of this matter, proposing a study on the one hand can highlight the features and the most important aspects of the evaluation and the other is able to demonstrate the operational validity of the latter in promote local development. The local development, in fact, becomes an important tool for the exploitation of resources of a territory, which takes an active role, offering more and more exploitable resources over time. Finally, it is exposed to the concept of "cultural system" as a model of spatial development can promote the economy of the area and the redevelopment and improvement of the overall livability of a given territory. The pattern of the district, in fact, is a reality for a long time active and dynamic in the industrial sector which today begins to be considered a great potential in the field of culture and urban development. The culture thus becomes an increasingly important role for territorial marketing in order to improve the quality of life and promote the attractiveness and competitiveness of the territory, in order to activate the factors necessary for its development. Concepts such as empowerment, innovation and creativity are, today, conditions that characterize the social, institutional, environmental and demographic constraints to economic growth of the postindustrialized countries. The Cultural District Evolved is based precisely on this assumption, for which this model aspires to become an important development trend in America, Europe and Italy. An example of a city that has been able to use culture as supporting its growth is Linz, a country capable of putting together a social progress, cultural and economic, as to be rated as one of the best achievements of the cultural district.

The second part is exposed to the project concerning the creation of the cultural system as a process of planning for the future development of the city. A project that involves many actors, especially citizens increasingly seen as behind the choices of a city more efficient. In the context of the current localization economies, in fact, cities are having to compete with each other in pursuit of a development in the long term through investment in the territory and citizens, as an impetus to innovation and research. The three assets to be followed in order to enhance the city will be the ones to make it more welcoming and attractive, with a strong relational identity, sustainable and innovative. Understand, then, as Reggio Calabria to respond to the characteristics of "cultural system" is the goal of this work. Understand what are the reasons that lead a reality, such as that in question, as if to better integrate, to make a place more innovative, both in terms of territorial and cultural, without losing sight of the centrality of the person, respect and protection of human dignity, freedom, and the promotion of interpersonal relationships.

\section{A resource to be exploited: the Pentimele's fortifications}

The city of Reggio Calabria has a wealth of cultural resources and tangible assets which refer to aspire to the achievement of development goals that would enable the city to improve its livability, increasing the level of quality of life, including through the use, and therefore, the proper use of these resources.

The first step in this direction is to become aware of the importance of this heritage, which must be expressed, first of all, through the protection and enhancement actions that do not make it a museum, but it Repeater wellness, all this, however, can't occur without to appropriate conservation measures, to ensure the continuation of this to future generations values, which, however, in most cases, are in state of deterioration that could compromise their existence. the importance of restoration projects, basic and crucial time for you to those processes may trigger the growth of the city. 


\section{The experience of the restoration project}

A working group created by the partnership formed by the PAU Department, the Heritage and Landscape Superintendence of the province of Reggio Calabria, the Reggio Calabria's municipality and the Association Friends of the Earth, has prepared a draft remediation and security of one of the two nineteenth-century fortifications, commonly called "Umbertine" (the term was coined "Forti Umbertini" on site and is not recognized neither the military nor the scientific community national/international studies the nineteenth-century fortifications) (Fig. 1) on the Pentimele's Hill in Reggio Calabria, Pellizzari's Battery, the project aimed to hinder the progress of the degradation process was prompted by the state of disrepair into which the site.

These architectures military are part of a wider system of fortifications designed and created by the General Committee of Defense of the State in the second half of the 'nineteenth century as a result of the unification of Italy, for the control of the Strait of Messina to prevent a feared landing in Sicily and the possible forcing of the Straits: 9 were built forts on the Calabrian coast and 14 on the Sicilian coast. The building is spread over 3 levels above ground and one basement, is protected by a moat and consists of

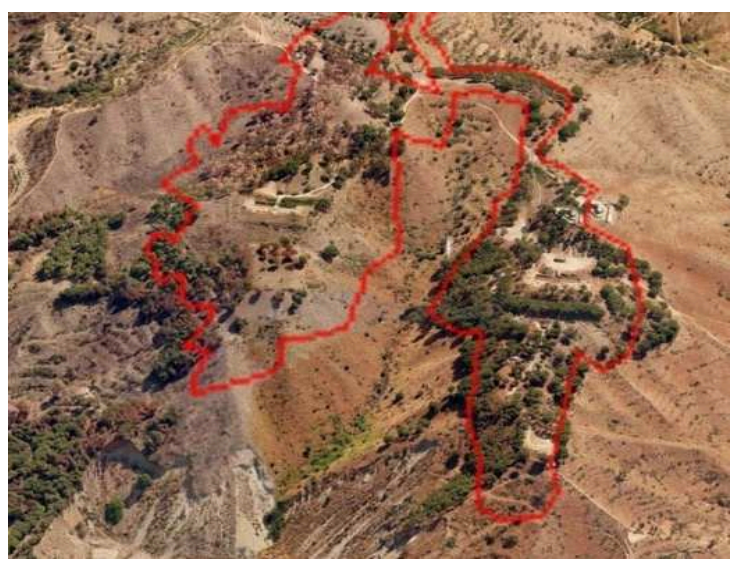

Fig.1, Intervent's area

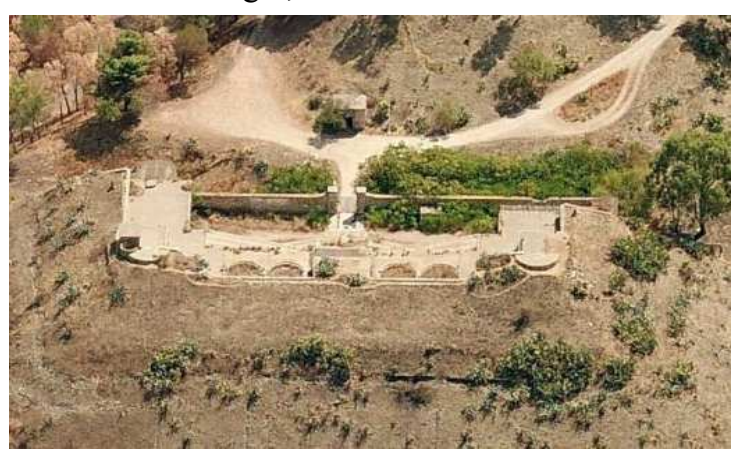

Fig.2, Pellizzari’s Battery a complex system environments (for the most part vaulted), many of which overlook the parade ground, equipped with ramps for transport of the guns at the top level in the slots prepared.

To the south, close to the underground tanks (such as the control room of the drawbridge in iron of which are to be used to cross the moat) are environments that have latrines; North compartments were used as dormitories and many others like deposits for the artillery, placed in communication via stairs or holes for the fast-approaching ammunition to the guns. A garrison of the structure at the level of the moat, is the caponier which allowed to control the moat and drawbridge through the slits. The entire building was built with rough-hewn stone curtain walls (limestone and sandstone) and appeals of bricks. They were designed as instruments of invincible military garrison, but in reality knew little use, and their presence constituted, in fact, a deterrent against the forcings by the Strait of enemy shipping. Between the end of the construction (completed in 1914 was the Fort of rails) and the air raids of 1943, the strong found their use during the First World War, between 1917 and 1918, who settled against German submarines in the waters Strait and II during the conflict when only eight of them remained active as a strong anti-ship, anti-aircraft emplacements implemented by [2]. On this occasion, the Pentimele's Forts, both the South, which suffered a lot of damage, both to the North, they were mostly used as storehouses for ammunition. In the years after the forts were used for military training exercises [3].

\section{State of preservation}

The Pellizzari's Battery is affected by degradation processes of various kinds, including, in addition to anthropogenic, the most dangerous for the safety of the structure is due to the presence of ruderal vegetation, in particular of ailanto [4]. This weed is a terrible threat to architectural heritage, in the context of the Forts it grows both inside the cavity of the tanks and behind the walls, and around the moat, weakening with its strong roots, the stability of the wall. Other types of weeds is the broom, which insinuates itself into the joints between an ashlar and the other, contributing to 
the phenomenon of absorption of water, stagnating into the wall, washes the mortar between the blocks and causes cracking, and the weakening and subsequent fall, the roots of stone slabs unplugging drains, not allowing them to perform the function of the convoy of the water away from the walls, water pooling inside the rooms causes swelling of the plaster accelerating the processes of detachment. As anthropogenic degradation are found, in addition to the presence of significant quantities of waste of different nature, written on the walls and many phenomena of vandalism that, repeated over time, have meant that the majority of fixtures wood (including the entrance gate of the which remain the cornerstones original) to protect the rooms were uprooted and destroyed.

Metal elements, such as the drawbridge and engagement rings of the guns, they are completely covered by surface deposits of rust. Currently all the strong (and surrounding area) is missing for any system of safety measures and equipment of any kind, totally away from the possibility of fruition.

\section{The criteria of the restoration project}

The conservation project before proposing any technical intervention must be developed through a careful analysis of the built-finding, without neglecting the assessment of its structural characteristics and the actual state of deterioration. After conducting this survey on the structure and the area where the building falls, they traced the lines of action (Fig. 3) aimed at the recovery of the physical methods closely by Forte a Nord respect both of the building techniques used and the context in which it is inserted adopting solutions with the least environmental impact and compatible materials and distinguishable from the original ones, if they are not reusable. Considering the impossibility

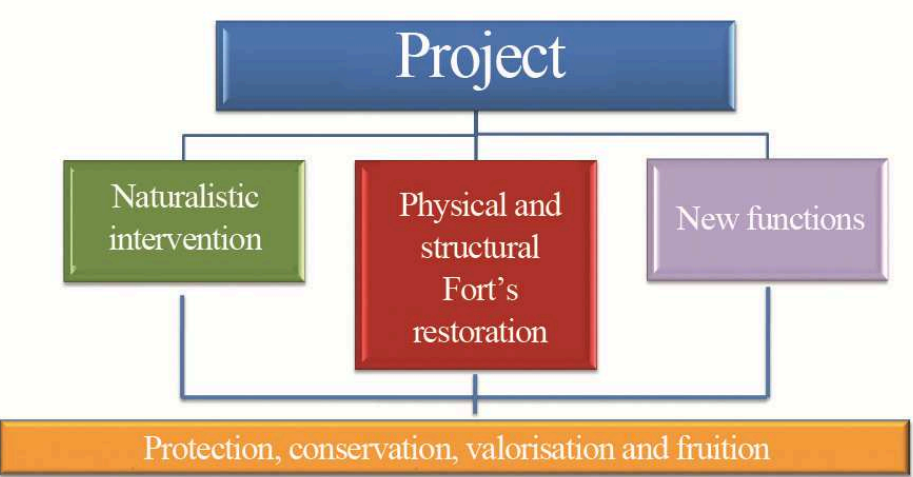

Fig.3, Project idea of preserving a historic building without any considerable new functions, being the only lasting reuse really effective weapon against degradation, it is expected reclamation and the safety of the entire structure to ensure its fruition.

In the first case there is a significant intervention in the natural reintegration of Pinus Pinea in areas that were previously affected by reforestation and currently are in a state of neglect, the area to renature today looks dry and lacking in continuity of the dislocation trees, it is the typical configuration of grassland steppe, a condition that has arisen because of the fires that have repeatedly devastated the hill.

The preliminary restoration operation involves the removal of the masses who do not belong to the plant walls, will be deleted after the ruderal vegetation and weed through the application of systemic chemicals. For reasons of greater efficacy and lower risk of injury to the substrate is preferred devitalizing a chemical treatment compared to only mechanical intervention, since the simple mechanical removal is not effective unless it can't remove the root systems in a complete manner, and also the 'direct excision of vegetating structures with significant roots and deep can damage the substrate for the resistance of the roots [5]. Within the Northern part of the fort, to solve problems related to moisture determined by the direct contact between the ground and the floor, we will proceed with the construction of a cavity under the floor to allow air circulation ventilation in the corridors defined by walls of bricks that support the various layers of decking. The passage of air will be allowed by the insertion of appropriate air intakes (rosettes aeration) in the wall. The paving slabs of limestone removed for the execution of the interspace, will be re-laid in place, in compliance with the originality of the structure.

The use of the site will be subject to safety measures, through the use of appropriate protective railings both inside the Fort is in the neighboring area, in order to ensure the proper use of these 
spaces together with an appropriate lighting and delimitation area to protect it from degrading any action $[6,7]$.

The intended use of the project for the environments of the area north of the fort will be the 'setup as a function of the creation of an information point or showrooms, in view of the organization of events and activities aimed at the promotion of the Hill and resources of the area, perhaps using the indirect form (being public property) for the management of the building.

\section{Acknowledgements}

The paper is the result of a consideration shared and the common effort of the authors. However, abstract, introduction and the paragraph The system design culture were treated by Carmen De Gaetano, and the paragraphs: Resource to be exploited: the Pentimele's fortifications, The experience of the restoration project, State of preservation, The criteria of the restoration project, were written by Tiziana Meduri and Carmela Tramontana.

\section{References}

[1] P. A. Valentino: Le trame del territorio. Politiche di sviluppo dei sistemi territoriali e distretti culturali, Piacenza (2003)

[2] V. Caruso: Messina nella Prima Guerra Mondiale, Edas, Messina (2008)

[3] V. Caruso, M. Lo Curzio: La fortificazione permanente dello Stretto di Messina: storia, conservazione e restauro di un patrimonio architettonico e ambientale, Messina, EDAS (2006)

[4] Pianta infestante, conosciuta come albero del paradiso per la sua tendenza a crescere notevolmente in altezza, si diffonde nel Meridione nel tentativo di intensificare l'allevamento dei bachi da seta, sull'esperienza portata avanti dalla Cina da cui proviene

[5] G. Haussmann, Piante infestanti e metodi di lotta, Bologna, Edagricole (1985)

[6] G. Carbonara: Trattato di restauro architettonico, vol. 3, Torino, UTET (2001)

[7] B. P. Torsello, Musso S. F.: Tecniche di restauro, Tomo II, Torino, UTET (2003) 